\title{
Fractal geometry and architecture: some interesting connections
}

\author{
N. Sala \\ Accademia di Architettura, Università della Svizzera italiana, \\ Mendrisio, Switzerland
}

\begin{abstract}
Some man-made objects are geometrically simple in that they resemble idealized forms such as lines, planes, cubes, or polyhedra. Ever since Euclid invented geometry, people have been content with the idea that all objects can be classified as compositions of regular geometric shapes. The architecture found inspiration by the Euclidean geometry and by the properties of the symmetry. The analogy between natural and architectural forms sometimes catches us profound impressions. Some architectural styles, for example the Baroque, found inspiration in nature, and it is not possible to describe nature using simple lines and curves. Nature is manifestly irregular and fractal-like. So perhaps we should not be so surprised to find fractal components in architecture. As we shall demonstrate, fractal geometry appears in architecture because it permits one to reproduce the complex patterns and the irregular forms present in nature. The aim of this paper is to present a fractal analysis applied to different architectural styles. We shall also introduce the fractal geometry applied in the large scale, describing some examples in the African and in the Oriental settlement architecture.
\end{abstract}

Keywords: fractals, architecture, self-similarity, urban organisation.

\section{Introduction}

In architecture it is usual to search the presence of geometrical and mathematical components. For example, the Euclidean geometry, the golden ratio, the Fibonacci's sequence, and the symmetry [1-7]. We can also observe the architecture using a different point of view, for example to find some complex or 
fractal components that are present in the buildings or in the urban planning [8-11].

The fractal geometry appears in architecture because it helps to reproduce the forms present in nature. Our fractal analysis has been divided in two parts:

- on a small scale analysis (e.g., to determine the fractal components in a building);

- $\quad$ on a large scale analysis (e.g., to study the urban organisation).

In the small scale analysis we observed:

- the building's self-similarity (e.g., a building's component which repeats itself in different scales),

- the Iterative Function Systems, IFS, (e.g., iterative fractal processes present in architecture).

In the large scale analysis we observed:

- the self-similarity in the settlement architecture,

- the fractal components present in the urban tissue.

Fractal components are present in different Gothic buildings, for example in the "Fractal" Venice [12], in the Gothic Cathedrals, and in the Baroque Churches, for example in the church of San Carlo alle Quattro Fontane (Rome), conceived by the Swiss architect Francesco Borromini (1599-1667). In this paper we present our analysis applied to different architectural styles. We shall also introduce the fractal geometry applied in the large scale describing some examples present in African settlement architecture (e.g., Mokoulek, Cameroon) and in the Oriental settlement architecture (e.g., Borobudur, Indonesia).

\section{Fractal geometry}

Fractal geometry is one of the most exciting frontiers in the fusion between mathematics and information technology. A fractal could be defined as a rough or fragmented geometric shape that can be subdivided in parts, each of which is approximately a reduced-size copy of the whole. The term fractal was coined by the Polish-born French mathematician Benoit B. Mandelbrot (b. 1924) from the Latin verb frangere, "to break", and from the related adjective fractus, "fragmented and irregular". This term was created to differentiate pure geometric figures from other types of figures that defy such simple classification. The acceptance of the word "fractal" was dated in 1975. When Mandelbrot presented the list of publications between 1951 and 1975, date when the French version of his book was published. The people were surprised by the variety of the studied fields: noise on telephone lines, linguistics, cosmology, economy, games theory, turbulence. The multiplicity of the fields of application has played a central role to the diffusion of Mandelbrot's discovery. Fractals are generally self-similar on multiple scales. So, all fractals have a built-in form of recursion. Sometimes the recursion is visible in how the fractal is constructed. For example, Cantor set, Sierpinski triangle, Koch snowflakes are generated using simple recursive rules. 


\subsection{The self-similarity}

The self-similarity is a property by which an object contains smaller copies of itself at arbitrary scales. A fractal object is self-similar if it has undergone a transformation whereby the dimensions of the structure were all modified by the same scaling factor. The new shape may be smaller, larger, translated, and/or rotated. "Similar" means that the relative proportions of the shapes' sides and internal angles remain the same. As described by Mandelbrot [13], this property is ubiquitous in the natural world [13]. Oppenheimer [14] used the term "fractal" exchanging it with self-similarity, and affirmed: "The geometric notion of selfsimilarity became a paradigm for structure in the natural world. Nowhere is this principle more evident than in the world of botany".

Self-similarity appears in objects as diverse as leaves, mountain ranges, clouds, and galaxies. Figure 1(a) shows a Koch curve, created using simple geometric rules. In the figure 1(b) is reproduced a broccoli (Brassica oleracea) which is an example of self-similarity in nature.

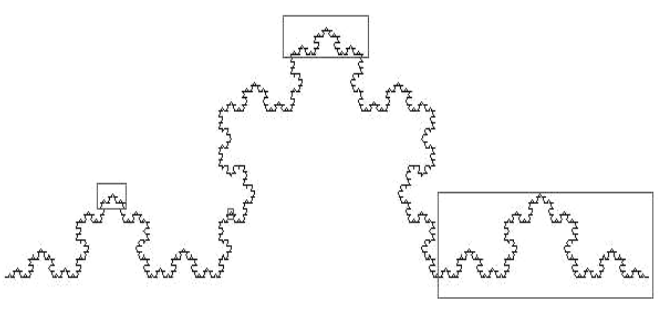

a)

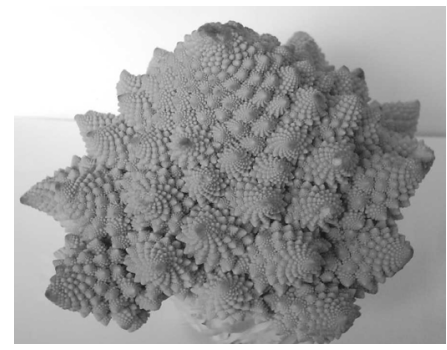

b)

Figure 1: $\quad$ Koch curve (a) and the broccoli (b) are fractals.

\subsection{The Iterated Function System}

Iterated Function System (IFS) is another fractal that can be applied in the architecture. Barnsley [15, p. 80] defined the Iterated Function System as follow: "A (hyperbolic) iterated function system consists of a complete metric space (X,

d) together with a finite set of contraction mappings $w_{\mathrm{n}}: \mathbf{X} \rightarrow \mathbf{X}$ with respective contractivity factor $s_{\mathrm{n}}$, for $\mathrm{n}=1,2, . ., \mathrm{N}$. The abbreviation "IFS" is used for "iterated function system". The notation for the IFS just announced is $\left\{\mathbf{X}, w_{\mathrm{n}}, \mathrm{n}\right.$ $=1,2, . ., \mathrm{N}\}$ and its contractivity factor is $s=\max \left\{s_{\mathrm{n}}: \mathrm{n}=1,2, \ldots, \mathrm{N}\right\} . "$

Barnsley put the word "hyperbolic" in parentheses because it is sometimes dropped in practice.

He also defined the following theorem [15, p. 81]: "Let $\left\{\mathbf{X}, w_{\mathrm{n}}, \mathrm{n}=1,2, \ldots, \mathrm{N}\right\}$ be a hyperbolic iterated function system with contractivity factor $s$. Then the transformation $W: \mathrm{H}(\mathbf{X}) \rightarrow \mathrm{H}(\mathbf{X})$ defined by:

$$
W(B)=\cup_{n=1}^{n} w_{n}(B)
$$


For all $\mathrm{B} \in \mathrm{H}(\mathbf{X})$, is a contraction mapping on the complete metric space $(\mathrm{H}(\mathbf{X})$, $\mathrm{h}(\mathrm{d}))$ with contractivity factor $s$. That is:

$$
\mathrm{H}(W(\mathrm{~B}), W(C)) \leq s \cdot h(B, C)
$$

for all $\mathrm{B}, \mathrm{C} \in \mathrm{H}(\mathbf{X})$. Its unique fixed point, $\mathrm{A} \in \mathrm{H}(\mathbf{X})$, obeys

$$
A=W(A)=\cup_{n=1}^{n} w_{n}(A)
$$

and is given by $A=\lim _{n \rightarrow \infty} W^{o n}(B)$ for any $\mathrm{B} \in \mathrm{H}(\mathbf{X})$."

The fixed point $A \in H(X)$, described in the theorem by Barnsley is called the "attractor of the IFS" or "invariant set".

Bogomolny [16] affirms that two problems arise. One is to determine the fixed point of a given IFS, and it is solved by what is known as the "deterministic algorithm".

The second problem is the inverse of the first: for a given set $A \in H(X)$, find an iterated function system that has $\mathrm{A}$ as its fixed point [16]. This is solved approximately by the Collage Theorem [15, p. 94].

The Collage Theorem states: "Let $(\mathbf{X}, \mathrm{d})$, be a complete metric space. Let $L \in \mathrm{H}(\mathbf{X})$ be given, and let $\varepsilon \geq 0$ be given. Choose an IFS (or IFS with condensation) $\left\{\mathbf{X},\left(w_{\mathrm{n}}\right), w_{1}, w_{2}, \ldots, w_{\mathrm{n}}\right\}$ with contractivity factor $0 \leq s \leq 1$, so that

$$
h\left(L, \cup_{\substack{n=1 \\(n=0)}}^{n} w_{n}(L)\right) \leq \varepsilon
$$

where $h(d)$ is the Hausdorff metric. Then

$$
h(L, A) \leq \frac{\varepsilon}{1-s}
$$

where A is the attractor of the IFS. Equivalently,

$$
h(L, A) \leq(1-s)^{-1} h\left(L, \underset{\substack{n=1 \\(n=0)}}{\cup} w_{n}(L)\right)
$$

for all $L \in \mathrm{H}(\mathbf{X})$."

The Collage Theorem describes how to find an Iterated Function System whose attractor is "close to" a given set, one must endeavour to find a set of transformations such that the union, or collage, of the images of the given set under transformations is near to the given set.

Next figure 2(a) shows a fern created using the IFS. The IFS is produced by polygons that are put in one another and show a high degree of similarity to nature. The polygons in this case are triangles.

Figure 2(b) illustrates the Collage Theorem applied to a region bounded by a polygonalized leaf boundary [15, p. 96]. 


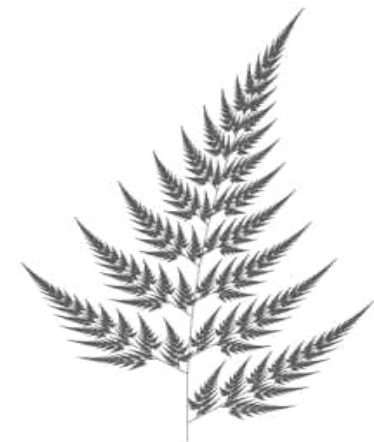

(a)

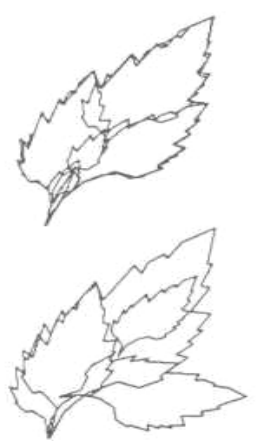

(b)
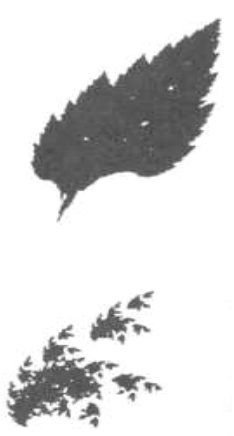

Figure 2: $\quad$ Fern created using the IFS (a). Collage Theorem applied to a region bounded by a polygonalized leaf boundary (b).

\section{Fractal geometry in architecture}

A discussion of fractal geometry applied in architecture can lead to ambiguous territory [17-19]. It is worthwhile mentioning that an architectural element is only approximately fractal, since it cannot have details that are infinitely small; thus, we prefer not to speak of "fractal architecture," but rather of architecture "with fractal components." This is in agreement with other studies [20].

\subsection{Self-similarity in architecture}

When we write about the presence of the self-similarity in architecture, we refer of a same shape repeated in different scales more than four times. We can classify the presence of the self-similarity in architecture in two different ways:

- unintentional, when the fractal quality has been chosen for an aesthetic sense (e.g., in the Hindu architecture);

- intentional, when the fractal component is, in every case, the result of a specific and conscious act of design (e.g., in the modern architecture).

It is interesting to analyze the self-similarity in different cultures and in different architectural styles (e.g., Hindu, and Gothic styles) and in different cultures (e.g., African and Oriental cultures).

Hindu temples present a fractal structure. The temple is the most characteristic artistic expression of Hinduism. The temple reflects the ideals and way of life of those who built it and for whom it was intended to operate a link between the world of man and that of the gods. In order to understand the architectural forms of the Hindu temple it is necessary to investigate the origins and development of the civilization that produced it. In older cultures the mountains prefigure the sacred sanctuaries around the world. In the Hindu experience the idea of the archetypal mountain of existence is mythologized in the cosmic mountain named Meru, the mythological center or navel of the 
universe. George Mitchell (1988) writes: "In the superstructure of the Hindu temple, perhaps its most characteristic feature, the identification of the temple with the mountain is specific, and the superstructure itself is known as a "mountain peak" or "crest" (shikhara). The curved contours of some temple superstructures and their tiered arrangements owe much to a desire to suggest the visual effect of a mountain peak" [21, p. 69]. Figure 3(a) shows an Indian temple, which presents fractal components.

In the Western architecture we can find the oldest handmade fractal object in the Cathedral of Anagni (Italy). Inside the cathedral, built in the year 1104, there is a floor, which is adorned with dozens of mosaics, each in the form of a Sierpinski gasket fractal.

The self-similarity is also present in the Gothic Cathedrals, as shown in figure 3(b). The Gothic is a style developed in northern France that spread throughout Europe between the $12^{\text {th }}$ and $16^{\text {th }}$ centuries. The term "Gothic" was first used during the later Renaissance by the Italian artist Giorgio Vasari (1511-1574), as a term of contempt. He wrote: "Then arose new architects who after the manner of their barbarous nations erected buildings in that style, which we call Gothic". Fulcanelli, the $20^{\text {th }}$ century most enigmatic alchemist, gave another explication of the term Gothic, which is connected to the language of the alchemy [18, p. 84].

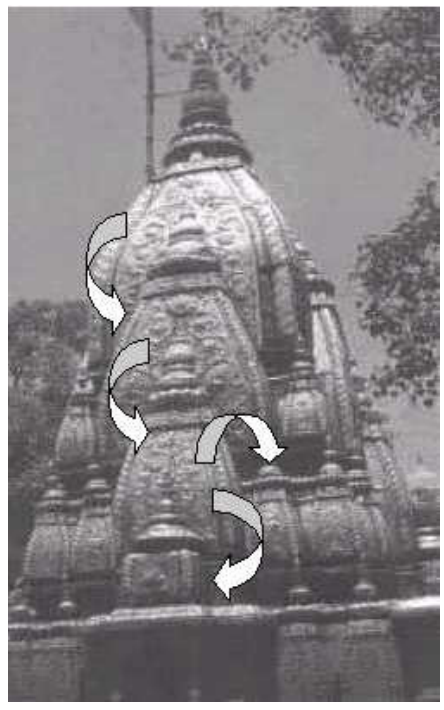

(a)

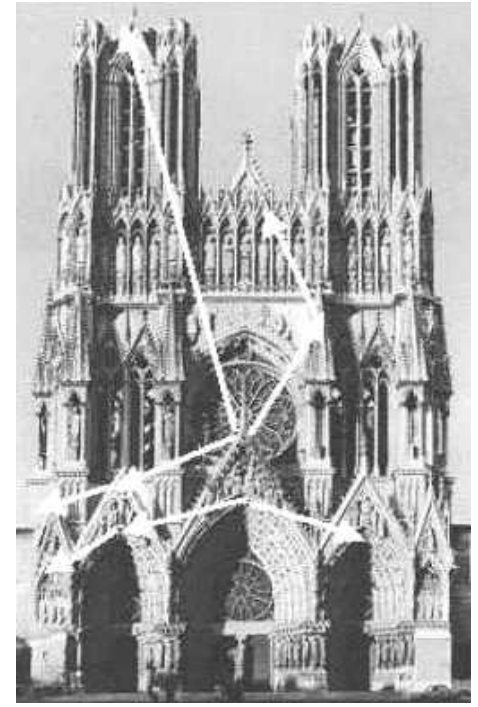

(b)

Figure 3: Hindu temple (a) and Gothic Cathedral (b) show the self-similarity.

The fractal geometry is present in the African culture. Ron Eglash, in his book entitled African Fractals (1998), presents a wealth of examples of fractals in African architecture, and design. Eglash points out that the African 
architecture reflects both the social and religious structure of the settlement. All the architectural examples exhibit fractal components as a consequence of some structural or organisational feature of the settlement. From a political perspective, Eglash writes: "Thus fractal architecture was used as colonial proof of primitivism. This debate over the urban status of non-Euclidean settlements continues in the postcolonial era" [22, p. 196].

He suggests that European settlers considered most African settlements to be large villages instead of cities, because instead of the Euclidean arrangements of European cities, they found complicated fractal arrangements. Figure 4(a) shows an aerial photograph of Ba-ila settlement, before 1944, situated in the Southern Zambia (Africa) [22, p. 27]. The settlement as a whole has the same shape: it is a ring of rings. Each extended family's home is a ring-shaped livestock pen, with a gate on one end. Progressing around the ring, the buildings become progressively larger dwellings, until the largest, the father's house, is opposite the gate (hence at the back of the pen). Figure 4(b) illustrates its fractal generation [22, p. 27].

Self-similar organisations are present in Mokoulek (Cameroon), one of the Mofou settlement, and in some Senegalese settlements.

Fractal components are also present in the Buddhist temples. Borobudur, the great Buddhist stupa on Java (Indonesia), built and decorated perhaps before $800 \mathrm{AD}$, should be on anybody's list of the ten greatest art-complexes in the world for its size, quality, sophistication and excellent state of preservation.

The structure, composed of 55,000 square meters of lava-rock, is erected on a hill in the form of a stepped-pyramid of six rectangular storeys, three circular terraces and a central stupa forming the summit. The whole structure is in the form of a lotus, the sacred flower of Buddha.

The temple at Borobudur shows some fractal components, in particular the self-similarity (figure 5(a)). It is certainly the world's largest mandala. Mandalas are sacred circular diagrams from the Tibetan tradition; an example is shown in figure 5(b).

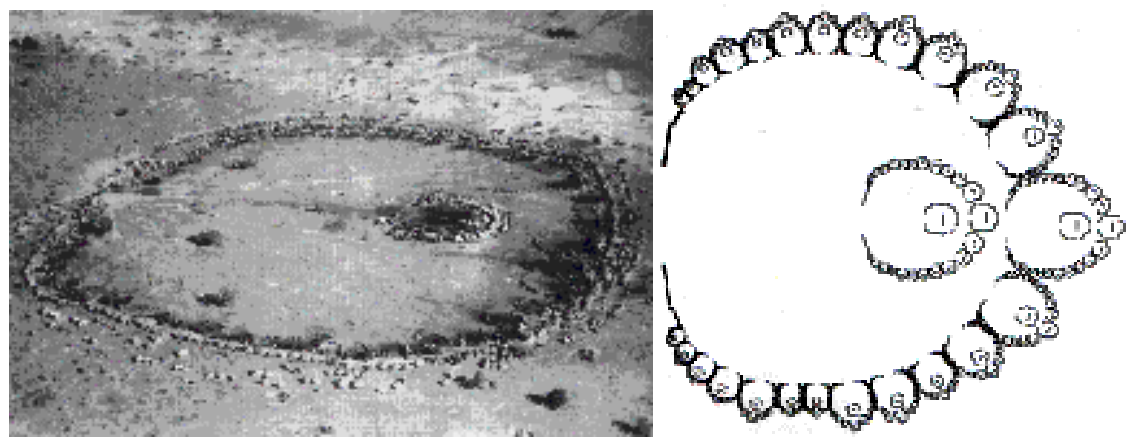

(a)

(b)

Figure 4: Ba-ila settlement (a) and its fractal organisation (b). 


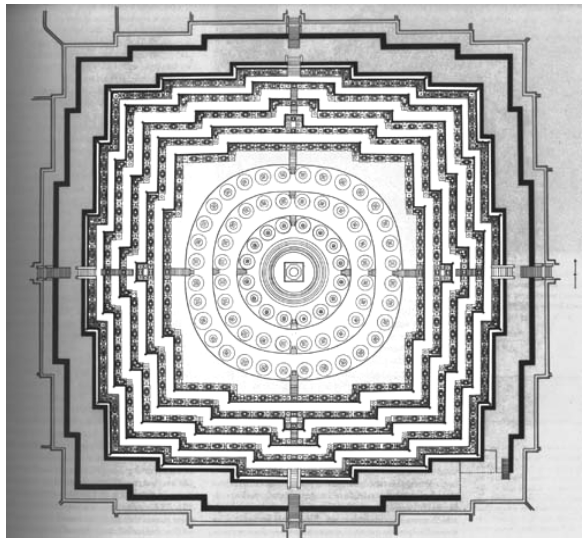

(a)

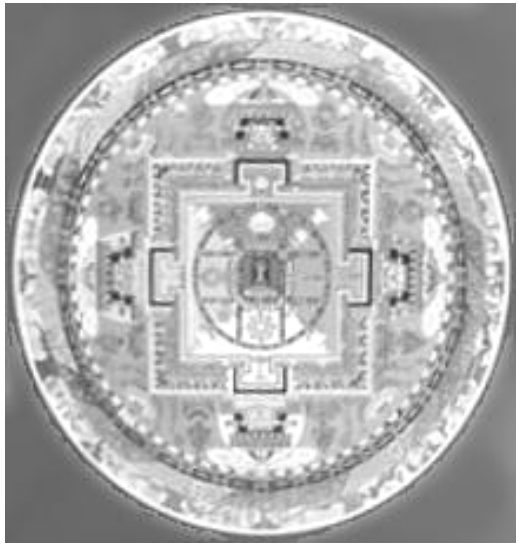

(b)

Figure 5: $\quad$ Borobudur (a) and the mandala (b) show the self-similarity.

\subsection{Iterated Function System in architecture}

Gothic architecture can be observed using the iterative function system. Figure 6(a) illustrates an attempt to find an IFS which could generate the ideal Gothic Church conceived by Eugène-Emmanuel Viollet-le-Duc (1814-1879). Figure 6(b) shows a fern generated by the computer using algorithms based on IFS.

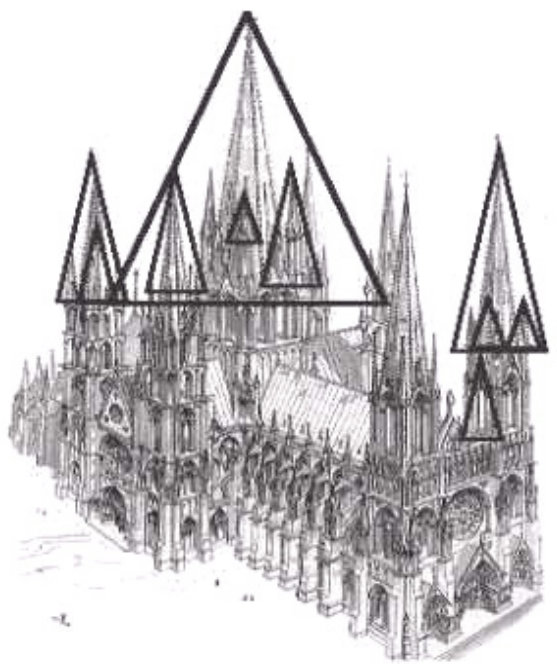

(a)

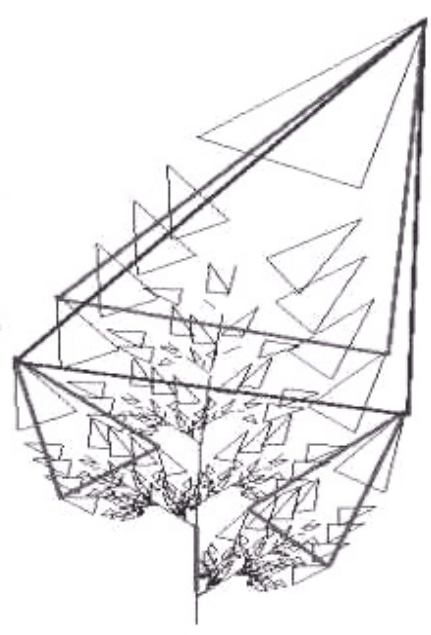

(b)

Figure 6: Ideal Gothic church (a), and the fern (b) could be generated using IFS. 
The Duomo (1386-1577, Milano), shown in figure 7(a), is the biggest and greatest late gothic architecture in Italy. The cathedral is white marble, over a brick core, and has a cruciform plan. One of the largest cathedrals in the world $(14,000$ square yards) it was designed to accommodate 40,000 worshippers. Figure 7(b) shows a Celosia Plumosa, which has the same fractal-like organisation of the facade of the Duomo.

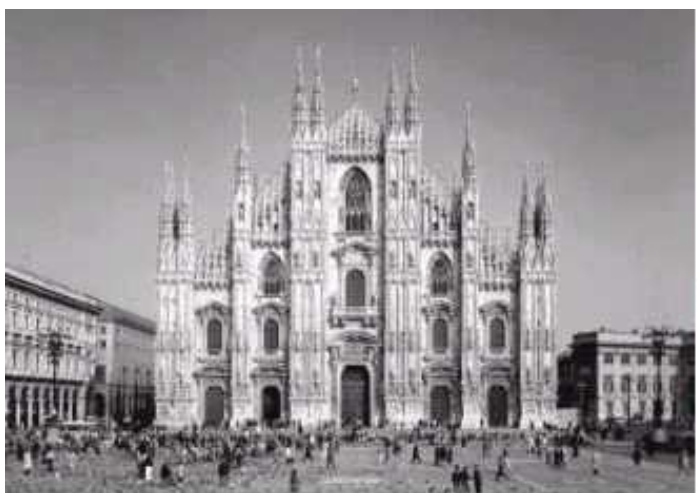

(a)

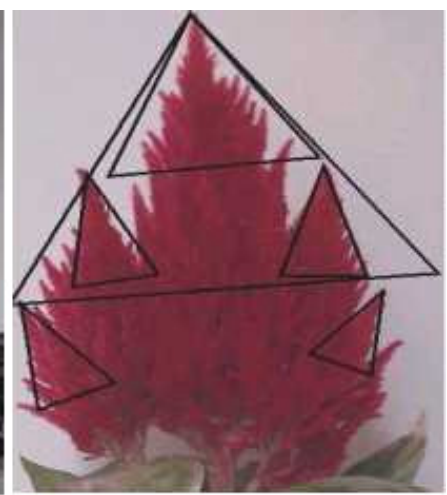

(b)

Figure 7: Duomo (Milano, Italy) (a), Celosia Plumosa (b) show the same fractal-like organisation.

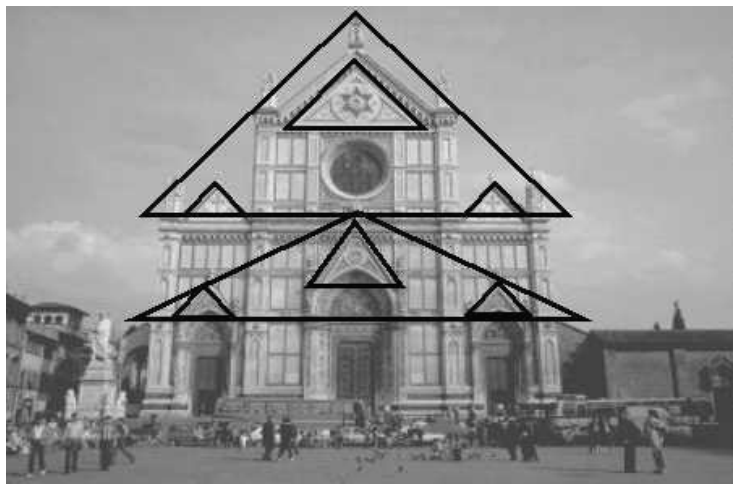

Figure 8: $\quad$ Santa Croce (Florence, Italy) an attempt to find the IFS.

Santa Croce, the church of the Franciscans in Florence, is one of the finest examples of Italian Gothic architecture. It was begun in 1294, in the period that served as the transition from Medieval times to the Renaissance. It was designed by Arnolfo di Cambio (1240-1302), and it was finished in 1442, with the exception of the $19^{\text {th }}$ century Gothic Revival facade and campanile. The church 
is simple basilica style with a nave and two isles. Figure 8 illustrates the west facade of Santa Croce, and an attempt to dissect it in triangles to find the IFS connected to the church.

The iterated function system applied to the Gothic cathedrals could help us to understand the generative processes of these complex buildings.

\section{Conclusions}

In the field of architecture, the fractal geometry is used in many ways: unintentionally and intentionally. In architectural design is important to provide harmony between old and new. Fractal geometry can be used in the process of supporting creativity in the ideation of new forms and for testing harmony between old and new. It is helping to define new architectural models and an aesthetic that has always lain beneath the changing artistic ideas of different periods, schools and cultures [9, 10, 17-20, 23-25].

The use of the iterated function system (IFS) for generating town-like patterns has been described by Woloszyn [26], who illustrates how the iteration of a simple substitution rule from an initial and basic pattern leads to an image that looks like an urban structure.

Recent studies introduce a genetic-like approach, allowing interpolation, alteration and fusion of different urban models, and leading to global or local synthesis of new shapes. These studies reveal that the IFS could help to create new pseudo urban models based on fractal algorithms [27]. Thus, it could be possible to encode simplified $2 \mathrm{D} \frac{1}{2}$ city models using an IFS compression technique.

\section{References}

[1] Blackwell, W., Geometry in Architecture, John Wiley \& Sons, London, 1984.

[2] Hargittai, I. \& Hargittai, M., Symmetry: A Unifying Concept, Random House, New York, 1996.

[3] Williams, K. (ed.), Nexus 1, Mathematics and Architecture, Edizione dell'Erba, Fucecchio, 1998.

[4] Badaway, A., Ancient Egyptian Architectural Design, University of California Press, Berkeley, 1965

[5] Williams K. (ed.), Nexus I1, Mathematics and Architecture, Edizione dell'Erba, Fucecchio, 2000.

[6] Sala, N. \& Cappellato, G., Viaggio Matematico Nell'Arte e Nell'Architettura, Franco Angeli, Milano, 2003.

[7] Dunlap R.A., The Golden Ratio and Fibonacci Numbers, World Scientific, Singapore, 1998.

[8] Venturi, R., Complexity and contradiction in architecture, The Museum of Modern Art, New York, 1992.

[9] Jencks, C., Complexity definition and nature's complexity, Architectural Design, n. 129, pp. 8-10, 1998. 
[10] Eaton, L.K., Fractal Geometry in the Late Work of Frank Lloyd Wright: the Palmer House. Nexus II: Architecture and Mathematics, ed. K. Williams, Edizioni Dell'Erba, Fucecchio, pp. 23-38, 1998.

[11] Sala, N., The presence of the Self- Similarity in Architecture: Some examples. Emergent Nature, M.M. Novak (ed.), World Scientific, Singapore, pp. 273-283, 2002.

[12] Fivaz, R., L'ordre et la volupté, Press Polytechniques Romandes, Lausanne, 1988.

[13] Mandelbrot, B., The Fractal Geometry of Nature, W.H. Freeman and Company, 1988.

[14] Oppenheimer, P., Real time design and animation of fractal plants and trees. Computer Graphics, 20(4), pp. 55-64, 1986.

[15] Barnsley, M.F., Fractals everywhere. Academic Press, Boston, $2^{\text {nd }}$ edition, 1993.

[16] Bogomolny, A., The Collage Theorem. Retrieved September 15, 2005 , from: http://www.cut-the-knot.org/ctk/ifs.shtml

[17] Ostwald, M.J., "Fractal Architecture": Late Twentieth Century Connections Between Architecture and Fractal Geometry, Nexus Network Journal, vol. 3, no. 1 (Winter 2001), http://www.nexusjournal.com /Ostwald-Fractal.html

[18] Sala, N. \& Cappellato, G., Architetture della complessità, Franco Angeli, Milano, 2004.

[19] Bovill, C., Fractal Geometry in Architecture and Design, Birkhäuser, Boston, 1996.

[20] Capo, D., The Fractal Nature of the Architectural Orders, Nexus Network Journal, vol. 6 no. 1 (Spring 2004), http://www.nexusjournal.com/ Capo.html

[21] Mitchell, G., The Hindu Temple: An Introduction to Its Meaning and Forms, University of Chicago Press, Chicago, 1988.

[22] Eglash, R., African Fractals, Rutgers University Press, New Brunswick, 1999.

[23] Jencks, C., The New Paradigm in Architecture. The Language of Postmodernism, Yale University Press, New Haven, USA, 2002.

[24] Soddu, C., Gencities and Visionary Worlds, C. Soddu (ed.), Generative Art 2005 Proceedings, pp. 11-24.

[25] Salingaros, N., Fractals in the New Architecture, Archimagazine, (2001), http://www.archimagazine.com/afrattae.htm

[26] Woloszyn, P., Caractérisation dimensionnelle de la diffusivité des formes architecturales et urbaines, Thèse, Laboratoire CERMA, Nantes, 1998.

[27] Marsault, X., Generation of textures and geometric pseudo-urban models with the aid of IFS, Chaos and Complexity Letters, vol. 1, n.3, Sala N. (ed.), Special issue dedicated to the Chaos and Complexity in Arts and Architecture, 2005, pp. 109-126 (in print). 